\title{
The Researching Mode Based on Generating Self-optimization of Global Optimization
}

\author{
Hua Zhigang ${ }^{*}$, Hu Guangyu, Wu Zhigong and Zhai Yongjie \\ Department of Business and Administration, North China Electric Power University, 102206, Beijing, China
}

\begin{abstract}
A method of global optimizing power generation is introduced in this paper. Under the condition of maintaining the same working hours of different units, electricity quantity generated between the different power suppliers is equal in one province, and it is also fulfilling the primary electricity schedule with a secure stable power system and low emission. This method is capable of minimizing resource consumption and emission while satisfying the power requirement by independently adjusting electricity generating units internally to optimum. Therefore, it is an important and effective way to promote energy saving in power generating and controlling.
\end{abstract}

Keywords: Boundary condition, generating self-optimization, global optimization, objective function, researching mode.

\section{INTRODUCTION}

Coal is the main source of generating electricity in the Chinese energy industry. In 2010, 1.6 billion tons of coal was consumed for electricity generation, which accounts for approximately $40 \%$ of the national coal consumption and generates $40 \%$ of sulphur dioxide and carbon dioxide emission. It has always been the main subject of energy saving and emission reduction in China. Between 2006 and 2010, coal consumption for electricity generation had been significantly reduced from $367 \mathrm{~g} / \mathrm{kWh}$ to $333 \mathrm{~g} / \mathrm{kWh}$, which had reached the highest level of the world, saving 391 million tons of coal and reducing 969 million tons of carbon dioxide emission and 8.37 million tons of sulphur dioxide emission. The average pollution emission and water consumption in electricity generation has also been remarkably reduced.

Up to 2015, coal-fired power will still be the main subject of energy saving. It is predicted that the power generating capacity in china will reach 1.437 billion $\mathrm{kW}$ in 2015 and soar to 1.885 billion $\mathrm{kW}$ in 2020 , of which the capacity of fossil fuel power plant will reach 1.2 billion $\mathrm{kW}$. The coal consumption per unit electricity will be reduced to 320 $\mathrm{g} / \mathrm{kWh}$ in 2020 which means it is increasingly harder to further reduce coal consumption per unit power.

Therefore, further energy saving and emission reduction in power industry should be achieved by improving power generation techniques and the structure of power supply. By applying independent power generation optimisation, the potential of saving energy and reducing emission in coalfired generation can be further expended.

\section{PRINCIPLE OF INDEPENDENT POWER GEN- ERATION OPTIMIZATION}

\subsection{Current Strategy of Independent Power Generation Optimization}

Current energy saving strategy in electricity generation is preferentially using clear energy as power source and using

\footnotetext{
*Address correspondence to this author at the No.28 Jingrong Street, Xicheng District, Beijing, China, 100033; Tel: (0086)18800001581; E-mail: 376669681@qqq.com
}

general coal-fired power plants as complement with schedule which is designed based on coal consumption. It is a power generating model built on the aim of maximising the use of renewable and clean energy and minimizing the consumption of fossil fuels basing on energy consumption and emission levels. In terms of coal-fired unit, it is an arrangement optimized by the generator units' efficacy of coal consuming [1].

\subsection{The Strategy of Independent Power Generation Op- timisation}

Independent power generation optimisation includes optimisation on power generating structure and process. Power generation structure optimization is an optimization based on the capacity of generators. On one hand, the proportion of the number and the power product of generators using clean energy will increase by improving the power generating structure. On the other hand, the efficacy of traditional energy will also improve by updating traditional power generating process and facility which would lower coal consumption for unit power. Power generating process optimization focuses on optimizing the power generation distribution and management [2].

By allowing some autonomy on power company management and maintaining the safety and stability of the grid, power quantity by contract can be exchanged and redistributed inside and between the power companies while the operational processes can also be improved to satisfy the electricity requirement with minimum resource consumption and emission.

\section{MODELLING INDEPENDENT POWER GENERA- TON OPTIMIZATON AND ITS BOUNDARY CONDI- TON}

Independent power generation optimization is the process of minimising resource consumption and emission while fulfilling the power requirement though independently adjusting internal electricity generating units to optimum, under the condition of maintaining the working hours of differ- 
ent units and the electricity quantity generated by different power suppliers in the same province while fulfilling primary electricity schedule with a secure stable power system and low emission.

\subsection{Modelling Independent Power Generation Optimiza- tion}

The target function of independent power generation optimization $[3,4]$ is:

$$
\max \left(\operatorname{function}\left(Q_{k}\right)=\max \left(\left(E_{k}-V_{k}\right) * Q_{k}\right.\right.
$$

Formula (1), Where $\mathrm{E}$ stands for electricity price, $\mathrm{V}$ is variable cost, $\mathrm{Q}$ as the quantity of electricity and $\mathrm{k}$ represents the number of generator unit.

Multiple restriction conditions are considered in the optimization: firstly, the restriction of electricity generating capacity of the power plants and the grid; secondly, the change of the cost resulted by improving internal capacity structure of the power generating group should not affect the terminal customers; thirdly, the benefit of shareholders must not be harmed.

\subsection{The Constraint Matrix of Independent Power Gen- eration Optimization}

Assuming the marginal cost of different power companies are different, independent power generation optimization transfers the quantity of electricity need to be generated by contract from the companies with high marginal cost to those with low marginal cost to lower the total cost of electricity generation. The marginal income is the income after subtracting the cost of fuel and consumable materials, excluding financial expenses, labour charge, administration expenses, depreciation and other costs [5].

Assuming that the quantity of electricity generated remains consistent after the optimization in a power plant, let $u$ be the power consumption rate of the power plant, $q_{i}$ as the quantity of electricity generated by each generator unit, $Q$ as the total electricity in the grid, $k$ as the number of generator unit in this facility and $I$ as the number of generator unit in other facilities [6], the relation of these variables can be described as:

$$
\sum q_{k}^{\prime}\left(1-u_{k}\right)+\sum q_{l}^{\prime \prime}\left(1-u_{l}\right)=Q
$$

The quantity of electricity generated by each facility after optimization must not be less than its minimum generation capacity $Q_{k, \min }$ and not be more than the maximum of its capacity and capacity constrained by the grid. Therefore:

$$
Q_{k, \text { min }} \leq \sum_{k=1}^{n} q_{k} \leq \min \left(Q_{k, \text { max }}^{\prime}, Q_{k, \text { max }}^{\prime \prime}\right)
$$

Where $Q_{k, \text { max }}^{\prime}$ is the quantity of electricity generated under maximum efficiency by the power plant in variable number of hours; $Q_{k, \max }$ is the maximum electricity constrained by the grid or the market.

The compliment profit of transferring electricity quota outside the facility should be equal to the marginal income of generating this electricity on quota.

\section{THE ECONOMIC MODEL OF ENERGY SAVING ELECTRICITY GENERATING AND ITS DUEL PROPOSITION}

Analysing the energy transformation from coal to electricity with econometric aspect, the process can be described as using coal as input cost $\left(m_{i}\right)$ to produce the electricity product $\left(q_{i}\right)$ that satisfies the requirement of the grid under the environment friendly emission constriction with a certain product transform rate $\left(\eta_{i}\right)$ of the facility and certain profit $\left(V_{i}\right)$ is generated by this process, which is $m_{i}^{*} \eta_{i}=q_{i}+V_{i}$. The investment of fixed assets and fixed costs are not considered here.

The function of minimising resource consumption is corresponding to the function of maximising income, which means maximising income is minimising resource consumption. The close relation between consumption function and production function is a kind of duality.

\subsection{The Constraint Condition of Energy Saving Electric- ity Generating Control}

In the aspect of energy saving electricity generating control, under the condition of generating the same quantity of electricity, the total consumption of coal should be minimized. Regardless of the distribution of electricity quota in $n$ generation facilities, the emission standard, safety check and customer requirement must be fulfilled before and after the optimization, which means $Q=\sum_{i=1}^{n} q_{i}$ should remain constant. In another word, $\sum_{i=1}^{n} q_{i}$ must be constant as a constraint condition.

\subsection{The Equivalent Proposition of Energy Saving Elec- tricity Generating Control}

It is aiming to satisfy the safety check of the grid using minimum coal consumption $\sum_{i=1}^{n} M_{i}$ to achieve greater social income after optimization [7].

$$
\begin{aligned}
& \text { Target function: } \min \left(\sum_{i=1}^{n} m_{i}\right) \\
& \text { Constrained matrix: }\left\{\begin{array}{c}
q_{i} \geq 0 \\
\sum_{i=1}^{n} q_{i}=Q \\
\sum_{i=1}^{n} V_{i} \geq V
\end{array}\right\}
\end{aligned}
$$

\subsection{The Dual Proposition of Energy Saving Electricity Generating Control}

When setting the plan for total electricity generation, the grid safety check should be satisfied and the total income after optimization $\sum_{i=1}^{n} V_{i}$ should be maximised by reducing the total coal consumption $\sum_{i=1} M_{i}$ to a point lower than coal consumption before optimization $M[8]$.

The total consumption of coal $\sum_{i=1}^{n} M_{i}$ is smaller or equal to the consumption of coal $M$ before optimization, makes $\sum_{i=1}^{n} V_{i}$ maximum [8]. 
Dual model target function: $\max \left(\sum_{i=1}^{n} V_{i}\right)$

Constraint matrix of the dual model: $\left\{\begin{array}{c}q_{i} \geq 0 \\ \sum_{i=1}^{n} q_{i}=Q \\ \sum_{i=1}^{n} m_{i} \geq M\end{array}\right\}$

Therefore, if the optimal solution of proposition in 4.3 is achieved the solution of proposition in 4.1 , which means independent power generation optimization, is another way to achieve energy saving electricity generation [9].

\section{ECONOMICS ON INDEPENDENT POWER GEN- ERATION OPTIMIZATION}

\subsection{The Goal of Minimising the Cost of Electricity Gen- eration}

In the market economy system, the law of value presents as the exchange value of commodities is determined by their value but also fluctuates around the value. Cost on coal, such as mining cost, environment expenses and investment on physical distribution will present as part of cost of electricity generation and will be paid by the power plant. Such cost can be minimised by independently optimising the electricity quota while maintaining total quantity of electricity generated and satisfying the constriction in the grid [10].

In the area operating independent power generation optimization, the power generation quota is distributed on the principle of maintaining the same working hour for all generator units, which follows the tradition to achieve fairness in the first assignment. Then the power generation group will demonstrate independent power generation optimization to allocate social resource effectively on the principle of energy saving and improving efficiency under the condition of satisfying the grid safety and low emission standard. In this way, the companies would invest more effort in energy saving so that the social resource consumption can be more easily reduced while the power requirement is satisfied.

\subsection{Solution Toward Profit Problem of Energy Saving Electricity Generation}

Independent power generation optimization is capable of substantially reducing the social cost of electricity generation while maintaining current electricity price so that no negative effect is caused to the market, customers and profit distribution between different power companies. The efficiency improvement of the companies and the energy saving and emission reduction for the society are achieved in this way [11].

Independent power generation facilitate the transformation of power generation distribution towards a coal saving and social recourse saving model, the transformation of a government plan model to a plan-market hybrid model and solve the profit distribution issue in energy saving electricity generation distribution. Therefore, under current market environment, it is a better way of encouraging independent energy saving electricity generation in power companies.

\subsection{Better Energy Saving and Emission Reduction Effect}

Differential electricity plan is the annual plan designed on the difference of capacity level and coal consumption level between different generator units. Although this method can reduce emission, the effect is limited by the lack of objective standard of designing differential electricity plan. It ignores the variety of different power companies, which leads to unfairness in primary profit distribution and, more critically, not be able to adjust profit conflict between power companies.

In contrast, independent power generation optimization achieves fairness in primary distribution under annual electricity generation plan. It is sophisticatedly and effectively operated by the companies according to the difference in cost so that the profit issue is resolved internally within the company group [12].

\subsection{Analysis on Productivity Potential and Economy}

Independent power generation optimization focuses on different efficacy and capacity of different generator units within the same power group in the same province. The optimization potential extends with the variety. Here is an example of 5 different power companies in one power group [13].

Table 1 shows that after independent power generation optimization, the coal consumption for unit electricity had been reduced from $315.89 \mathrm{~g} / \mathrm{kWh}$ to $306.47 \mathrm{~g} / \mathrm{kWh}$ while the amount of electricity generated remains the same.

Table 1. Coal consumption before and after optimization in 5 companies.

\begin{tabular}{|c|c|c|c|c|c|c|c|}
\hline & $\begin{array}{c}\text { Capacity } \\
(\mathbf{M W})\end{array}$ & $\begin{array}{c}\text { Electricity Price } \\
(\mathbf{C N Y} / \mathbf{M W h})\end{array}$ & \multicolumn{2}{c|}{$\begin{array}{c}\text { Coal Price } \\
(\mathbf{C N Y} / \mathbf{t o n})\end{array}$} & \multicolumn{2}{|c|}{ Quantity of Electricity (GWh) } & \multicolumn{2}{c|}{ Coal Consumption (g/kWh) } \\
\hline \hline & & & & Before & after & before & after \\
\hline Power plant1 & 300 & 444 & 975.00 & 27134 & 20790 & 330.64 & 330.64 \\
\hline Power plant2 & 300 & 473 & 887.00 & 48376 & 44502 & 335.39 & 335.39 \\
\hline Power plant3 & 1000 & 441 & 914.00 & 123339 & 210409 & 291.58 & 291.58 \\
\hline Power plant4 & 300 & 446 & 937.00 & 114059 & 38073 & 325.36 & 325.36 \\
\hline Power plant5 & 130 & 445 & 956.26 & 12738 & 11962 & 362.83 & 362.83 \\
\hline Total & 2030 & 446 & 924.52 & 325656 & 325656 & 315.49 & 306.45 \\
\hline
\end{tabular}


Table 2. Economic benefit before and after optimization in 5 companies.

\begin{tabular}{|c|c|c|c|c|c|c|}
\hline & \multicolumn{2}{|c|}{ Unit Marginal Income (CNY/ MWh) } & \multicolumn{2}{|c|}{ Marginal Income (million CNY) } & \multicolumn{2}{|c|}{ Coal Consumption (kiloton) } \\
\hline plant2 & 54.96 & 60.57 & 2662 & 2704 & 16 & 15 \\
\hline plant3 & 47.04 & 51.63 & 5803 & 10873 & 35 & 60 \\
\hline plant5 & 32.79 & 33.56 & 415 & 401 & 5 & 4 \\
\hline summary & 43.63 & 47.06 & 14202 & 15332 & 101 & 98 \\
\hline
\end{tabular}

Table 2 shows that after independent power generation optimization, total marginal income increased from 14.208 million CNY to 15.339 million CNY while coal consumption dropped from 1030 kiloton to 990 kiloton.

Therefore, considering the fact that China generated electricity 3896.5TWh using coal on an efficient rate of 331 $\mathrm{g} / \mathrm{kWh}$ which consumes 127 million tons of coal, fully applying independent power generation optimization in the whole country could reduce coal consumption up to 10.2 million ton annually.

\section{CONCLUSION}

The method mentioned here can improve the current electricity generation method. Based on primary distribution of electricity generation, optimizing internal power generation plan within power company group can achieve minimum social resource consumption by allowing more electricity generated by the high efficiency generators. Independent power generation optimization requires no reformation on power system and no extra cost and has no negative effect on the grid safety and companies benefit from it. This method is beneficial to both, companies and the whole society, with high practicability and principle. Therefore, it is an important and effective way of promoting energy saving electricity generation control.

\section{CONFLICT OF INTEREST}

The authors confirm that this article content has no conflict of interest.

\section{ACKNOWLEDGEMENTS}

Declared none.

\section{REFERENCES}

[1] R.A. Jabr and B.C. Pal, "Intermittent wind generation in optimal power flow dispatching," Generation, Transmission \& Distribution, IET, vol. 3, pp. 66-74, 2009.
[2] B. Zhang, W.C. Wu, and T.Y. Zhang, "Design of a multi-time scale coordinated active power dispatching system for accommodating large scale wind power penetration, "Automation of Electric Power Systems, vol. 35, no. 1, pp. 1-6, Jan. 2011.

[3] F. Kahrl, J. Williams, and J. Hu, "The political economy of electricity dispatch roform in China," Energy Policy, vol. 53, pp. 361369, 2013.

[4] Y.C. Zhou, Y. Li, and B.B. Wang, "Impact of two dispatching methods on AGC unit dispatch in electricity market environment," Power System Technology, vol. 34, no. 7, pp. 154-159, Jul. 2010.

[5] S. Zhang, C.W. Taft, J. Bentsman, A. Hussey, and B. Petrus, "Simultaneous gains tuning in boiler/turbine PID-based controller clusters using iterative feedback tuning methodology," ISA Transactions, vol. 51, no. 5, pp. 609-621, 2012.

[6] T. Abrudan, J. Eriksson, and V. Koivunen, "Steepest descent algorithms for optimization under unitary matrix constraint", IEEE Transactions on Signal Processing, vol. 56, no. 3, pp. 1134-1147, Mar. 2008.

[7] Z. W. Gao, and H. Wang, "Descriptor observer approaches for multivariable systems with measurement and diagnosis," Systems and Control Letters, vol. 55, no. 4, pp. 304-313, 2006.

[8] H. Zhang, Y. Shi, and A.S. Mehr, "Robust static output feedback control and remote PID design for networked motor systems," IEEE Trans Industrial Electronics, vol. 58, pp. 5396-405, 2011.

[9] M. Basu, "Economic environmental dispatch using multi-objective differential evolution," Applied Soft Computing, vol. 11, no. 2, pp. 2845-2853, Mar. 2011.

[10] P. Mago, and L. Chamra, "Analysis and optimization of cchp systems based on energy, economical, and environmental considerations," Energy and Buildings, vol. 41, no. 10, pp. 1099-1106, 2009.

[11] M. Basu, "Economic environmental dispatch using multi-objective differential evolution," Applied Soft Computing, vol. 11, no. 2, pp. 2845-2853, Mar. 2011.

[12] H. Ren, and W. Gao, "Economic and environmental evaluation of microchp systems with different operating modes for residential buildings in Japan," Energy and Buildings, vol. 42, no. 6, pp. 853$861,2010$.

[13] J. Ma, "On-grid electricity tariffs in China: development, reformand prospects," Energy Policy, vol. 39, no. 5, pp. 2633-2645, 2011. 